\title{
ELONGATION AND LOAD DEFLECTION CHARACTERISTICS OF REINFORCED CONCRETE MEMBERS CONTAINING PLASTIC HINGES
}

\author{
R. C. Fenwick ${ }^{1}$ and L. M. Megget ${ }^{1}$
}

\begin{abstract}
In regions, described as plastic hinge zones, in beams and columns, tensile yielding of the reinforcement through flexural action can occur in severe earthquakes. Where the beams and columns are lightly loaded, axially, member elongation can occur. Test results show that axial extensions of the order of several percent of the member depth may be expected. This deformation, which is ignored in current design practice, can have a major influence on the distribution of forces in a structure and its ability to survive without collapse. This paper describes the way in which elongation develops in plastic hinge zones together with the form of load deflection characteristics associated with the development of different types of plastic hinge zone.
\end{abstract}

\section{INTRODUCTION}

Once flexural cracking occurs in a reinforced concrete member elongation occurs unless it is restrained axially. This elongation arises as the tensile strains in the flexural reinforcement are greater than the compressive strains in the concrete. In Figure 1 a beam, which is restrained against rotation at each end but not against axial extension, is shown subjected to transverse load. In the mid regions of the span, where the beam is sustaining positive bending moments, the neutral axis lies above the mid-depth of the member, while in the negative bending moment zones it lies below this line. From this illustration it can be seen that the mid-depth line is in a tension zone over its full length, which indicates the member extends. In many practical situations this elongation is restrained by the surrounding structure and as a result axial forces are induced.

With the formation of plastic hinge zones, such as are expected to occur in ductile structures in a major earthquake, elongation increases due to the extensive tensile yielding of the reinforcement.
The structural actions associated with elongation have received relatively little attention in the literature. This is in part due to the fact that elongation induced effects only become important in indeterminate structures, which are seldom tested in laboratories due to the cost involved. In simulated seismic lateral load tests on a number of two bay reinforced concrete frame sub-assemblies Zerbe and Durrani $(1,2)$ noted that elongation occurred and that it had a marked influence on the structural behaviour. In these tests the elongation effects were accentuated by the restraint provided by the loading system that was employed. In the test of a seven storey building, where the lateral force resistance was provided by a combined frame-wall system, the elongation of the wall due to the formation of a plastic hinge at its base, was found to lead to a substantial increase in strength. In this case the elongation induced axial compression in the wall and axial tension in a number of the surrounding columns(3).

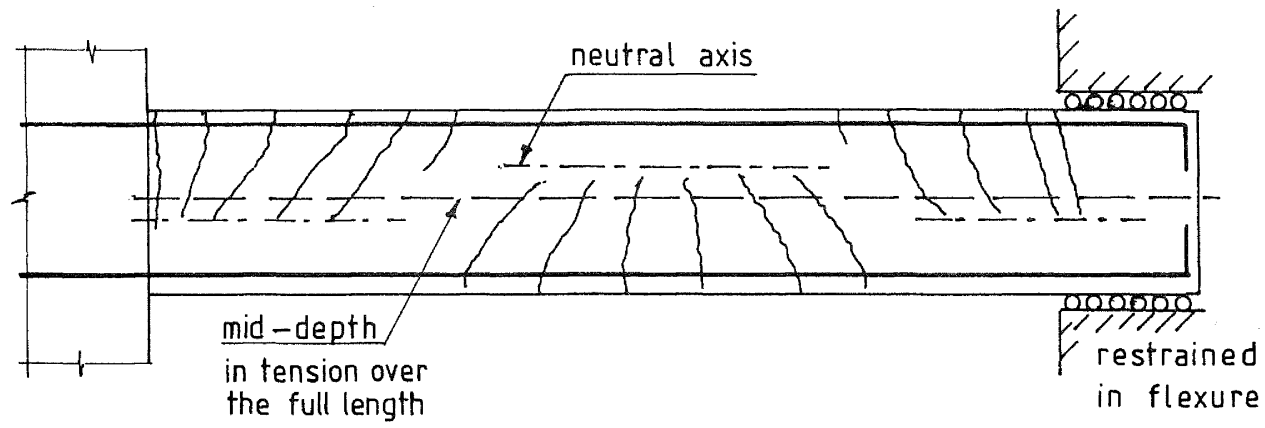

Figure 1 Elongation of a reinforced concrete beam subjected to flexure.

\footnotetext{
${ }^{1}$ Dept. of Civil Engineering, University of Auckland, New

Zealand. (Fellow)
} 
Elongation occurring in reinforced concrete beams has been recorded in a number of tests on beams, beam-column and frame sub-assemblies $(4,5,6)$. These have shown that plastic hinge zones, which are not restrained against axial extension, may be expected to sustain elongation of between 2 and 5 percent of the beam depth before strength degradation occurs.

Two different forms of plastic hinge zone may develop in a ductile structure. In beams, which support only light gravity loads along their length, and in structural walls and columns it is anticipated that the plastic hinge zones, which form in a severe earthquake, are subjected to inelastic deformation involving both positive and negative rotations. These are referred to as "reversing plastic hinges". In frames, where the beams support more than a critical gravity load, along their length, the positive and negative moment plastic hinges develop in different locations. In such cases as the structure sways backwards and forwards inelastic negative moment rotations accumulate in the beams at the column faces while the positive moment inelastic rotations accumulate in the span of the beam. These are referred to as "uni-directional plastic hinges". This form of hinge may be expected to occur in a severe earthquake in a large proportion of the beams in frame structures where the frames have been designed for the dual purpose of providing both seismic and gravity load resistance.

\section{FORMATION of UNI-DIRECTIONAL PLASTIC HINGES}

The formation of uni-directional plastic hinges in a beam of a seismic resistant frame is illustrated in Figure 2. As the structure sways to the right hand side, as shown in Figure 2(a), a negative moment plastic hinge forms at the face of the right hand column while a positive moment plastic hinge forms to the left of mid-span. When the direction of sway reverses, as is illustrated in Figure 2(b), a negative moment plastic hinge forms in the beam at the face of the left hand column and a further positive moment hinge forms in the span to the right of the midspan position. The bending moment diagrams associated with sway in both directions are shown in Figure 2(c).

With each subsequent inelastic lateral deflection of the structure additional rotation accumulates in the hinge zones giving rise to the deflected shape shown in Figure 2(d). The performance of structures containing uni-directional hinges has been examined both analytically(7) and experimentally(5) and it has been shown that to survive a major earthquake the plastic hinges must sustain high rotations.

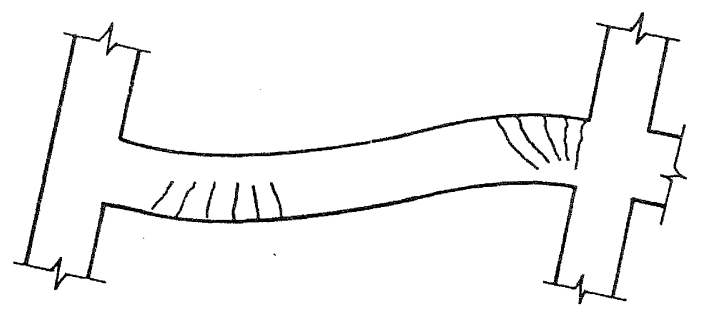

(a) Sway to right

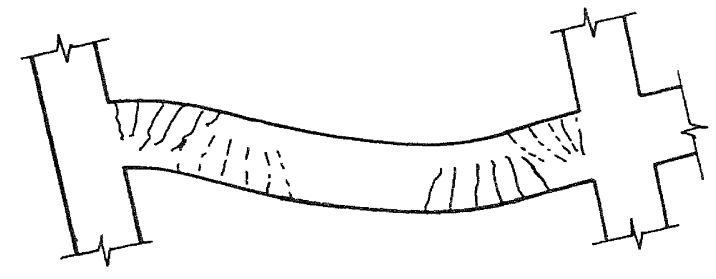

(b) Sway to left

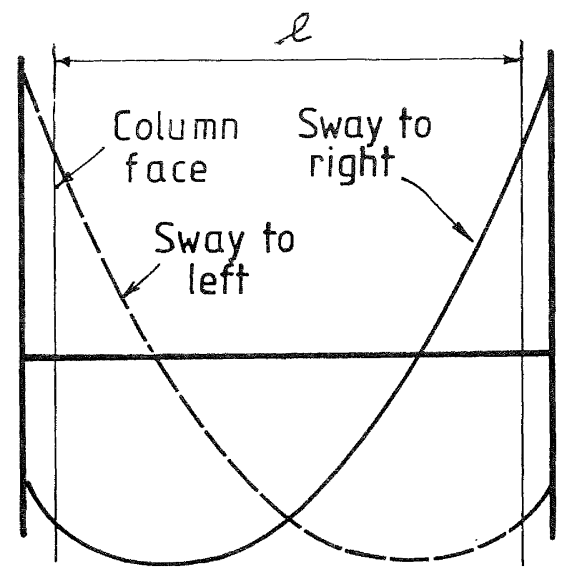

(c) Bending moments

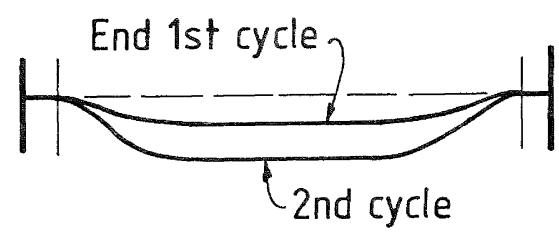

(d) Deflected shape

Figure 2 Uni-directional plastic hinges in a beam. 


\section{FORMATION of REVERSING PLASTIC HINGES}

Numerous tests have been made to examine the performance of reversing plastic hinge zones in concrete structures. However, in only a few of these have measurements been made of the associated axial deformation $(1,4,5,6)$.

The way in which reversing plastic hinge zones form in the beams of a frame in a severe earthquake is illustrated in Figure 3. As the structure sways to the right, as shown in Figure 3(a), positive and negative moment plastic hinges form in the beam against the left and right hand column faces respectively. With a change in the direction of sway, as illustrated in Figure 3(b), the direction of inelastic rotation sustained by each of the plastic hinge zones reverses. The bending moment diagrams associated with each direction of sway are shown in Figure 3(c). In this case, as illustrated in Figure 3(d), the deflected shape does not change with subsequent load cycles.

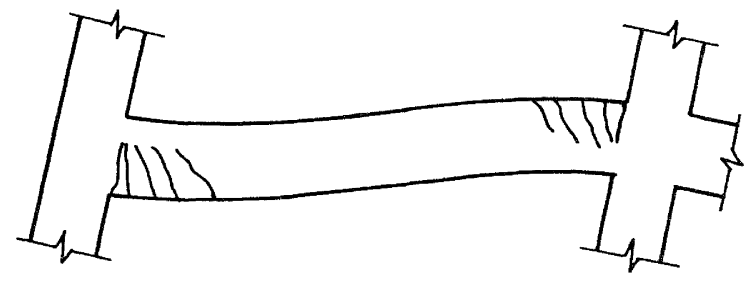

(a) Sway to right

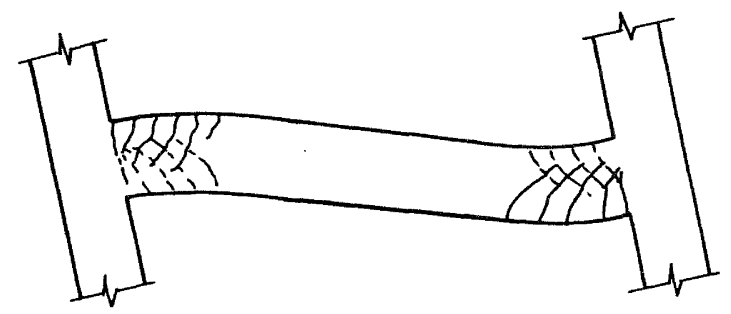

(b) Sway to left
Reversing hinges may be expected to form in a beam in a severe earthquake provided the maximum positive and negative bending moments occur at the ends of the member. There is one situation where this criterion may not apply and that is where some of the positive bending moment flexural reinforcement is terminated near the column faces. With this exception the maximum uniformly distributed load, $w$, that the beam can sustain and still form reversing hinges is given by-

$$
w=2\left(M_{a}+M_{b}\right) / \ell^{2}
$$

where $M_{a}$ and $M_{b}$ are the maximum positive and negative flexural strengths at each end of the member and $\ell$ is the clear span between the column faces (see Figure 3(e)). It should be noted that in this situation $w$ is the uniformly distributed force on the beam which will vary due to the interaction of the structure with the vertical ground accelerations. If the distributed force exceeds the value given by equation 1 unidirectional hinges will form.

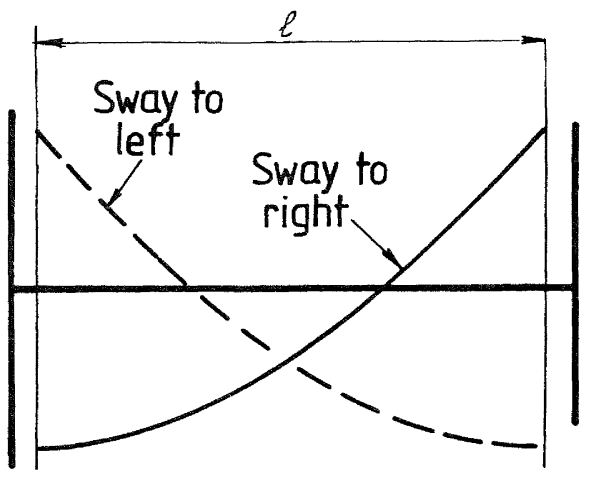

(c) Bending moments

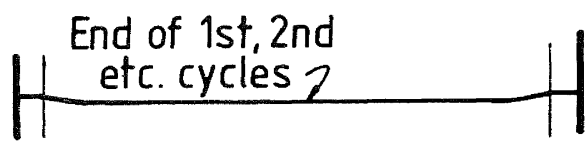

(d) Deflected shape

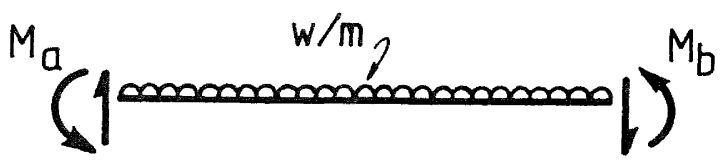

(e) Equilibrium requirement

Figure 3 Reversing plastic hinges in a beam. 
COMPARATIVE TEST RESULTS ON UNI-DIRECTIONAL and REVERSING PLASTIC HINGES

Two identical beams were made and tested to enable the performance of uni-directional and reversing plastic hinges to be compared. The details of these are given in Figure 4 together with some details of the instrumentation that was used in the tests. The stirrups were designed to sustain the maximum shear that the beam could resist allowing for strain hardening of the longitudinal reinforcement; they also provided restraint against buckling of the flexural reinforcement.

Two $12 \mathrm{~mm}$ bars were fillet welded to each longitudinal $28 \mathrm{~mm}$ bar, as indicated in the figure, to ensure that the yielding did not extend into the springing block. The pattern of displacement transducers used enabled the flexural and shear displacements to be calculated together with the elongation of the beam.

At the start of both tests two elastic load cycles where applied. In these the maximum load applied in the downward and upward directions was limited to the value which gave a bending moment equal to three quarters of the theoretical flexural strength at the critical section of the beam. The average of the four peak deflections obtained in the first beam that was tested was divided by three quarters to calculate the displacement corresponding to a displacement ductility of one at the loading point $(1 \mu)$. This value was used for both beams.

In the first beam, following the elastic load cycles, the loading consisted of applying pairs of load cycles in which the maximum downward displacement (half cycles $\mathrm{i}$ and ii) was limited to a predetermined displacement ductility and the upward loading (half cycles $-i$ and -ii) was limited so that the maximum bending moment induced was equal to three quarters of the theoretical flexural strength. In the first pair of load cycles the downward displacement was set at a displacement ductility of two. In subsequent load cycle pairs this limit was increased to $4,6,8$, etc. Failure, due to compression steel buckling, occurred in the first cycle to a displacement ductility of 14 .

In the second beam the elastic load cycles were followed by a pair of load cycles in which the displacement varied from displacement ductilities of +2 , ( $\mathrm{i}$ and ii) to -2 , ( $-\mathrm{i}$ and $-\mathrm{ii}$ ). This was followed by further pairs of load cycles in which displacement corresponded to $\pm 4, \pm 6$ and \pm 8 , where positive ductilities represent downward loading. Failure, predominantly due to shear degradation, occurred in the first cycle to a displacement ductility of +10 .

Some of the measurements made on the plastic hinge zones of these two beams are shown in Figure 5. For the beam with the uni-directional plastic hinge it can be seen that the reinforcement in the compression zone sustains negligible strain provided it has not yielded in tension in a previous load cycle, see Figure 5(a).

Assuming that this strain is zero the elongation at the mid-depth level can be calculated from the expression -

$$
\text { extension }=\Sigma \theta\left(\mathrm{d}-\mathrm{d}^{\prime}\right) / 2
$$

where $d-d^{\prime}$ is the distance between the centroids of the flexural reinforcement and $\Sigma \theta$ is the sum of the plastic hinge rotations in the beam. In this test there is only one hinge. This equation was derived in an earlier paper(5).
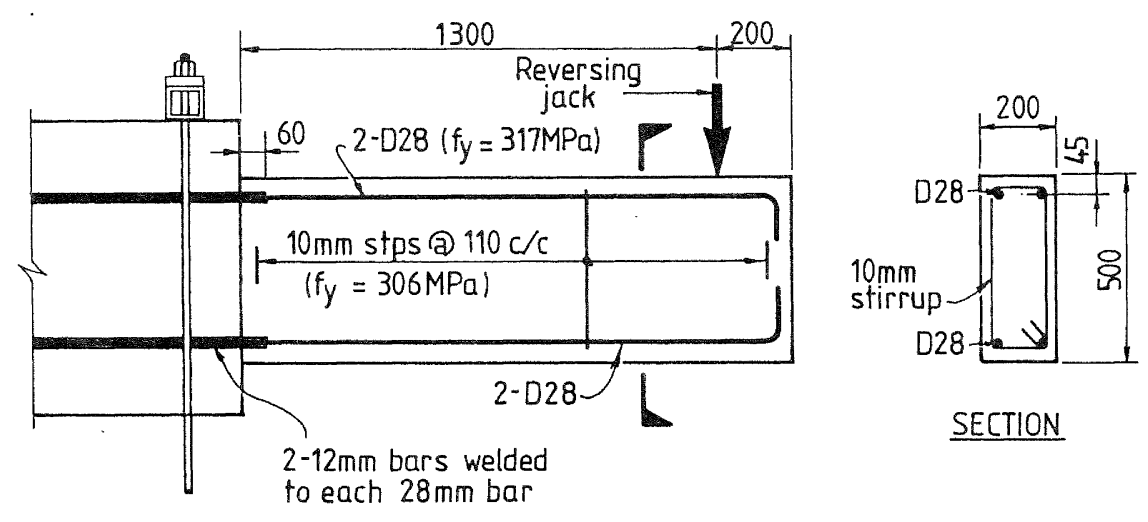

(a) Beam dimensions and reinforcement details
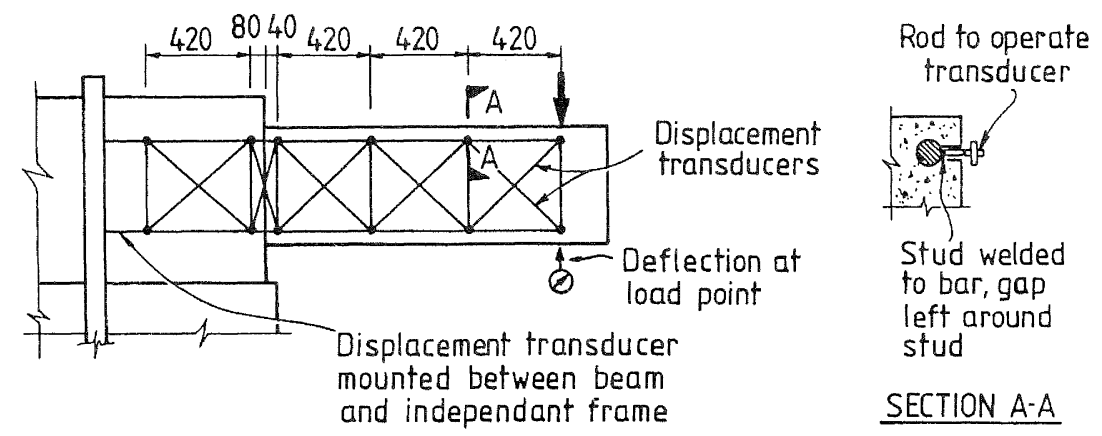

(b) Instrumentation on beam

Figure 4 Details of test beams. 

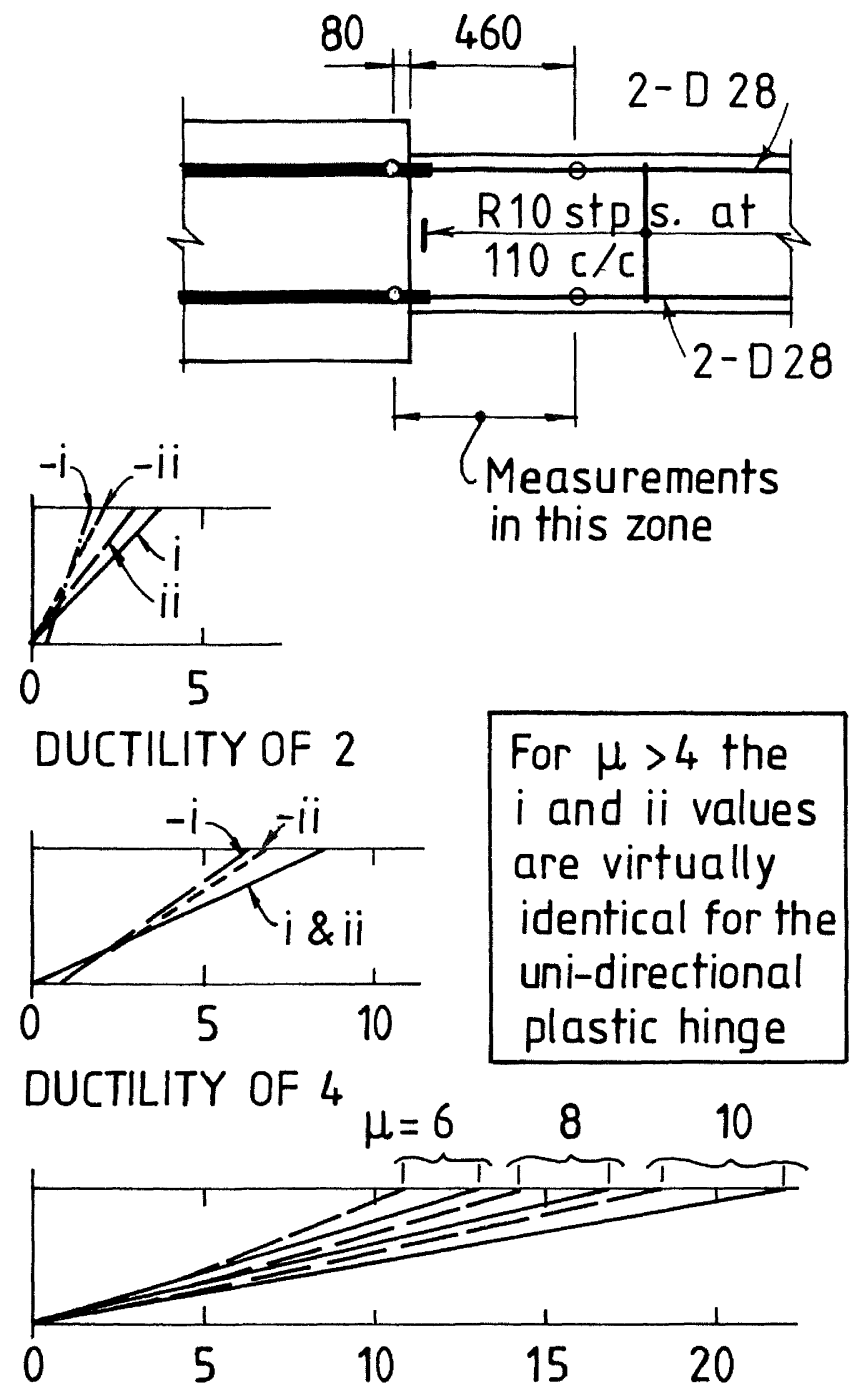

DUCTILITY OF $6,8 \& 10$

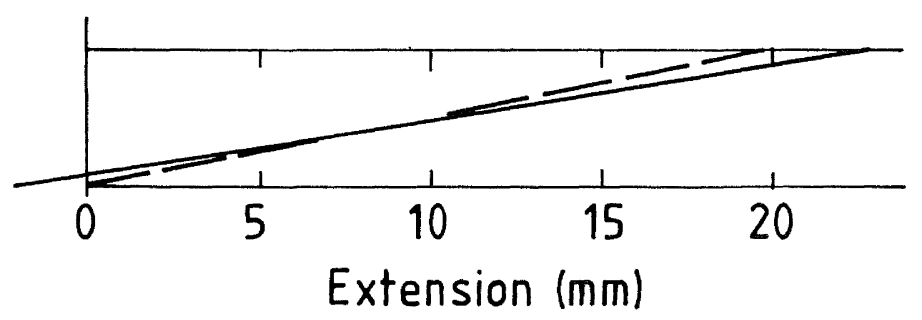

DUCTILITY OF 12
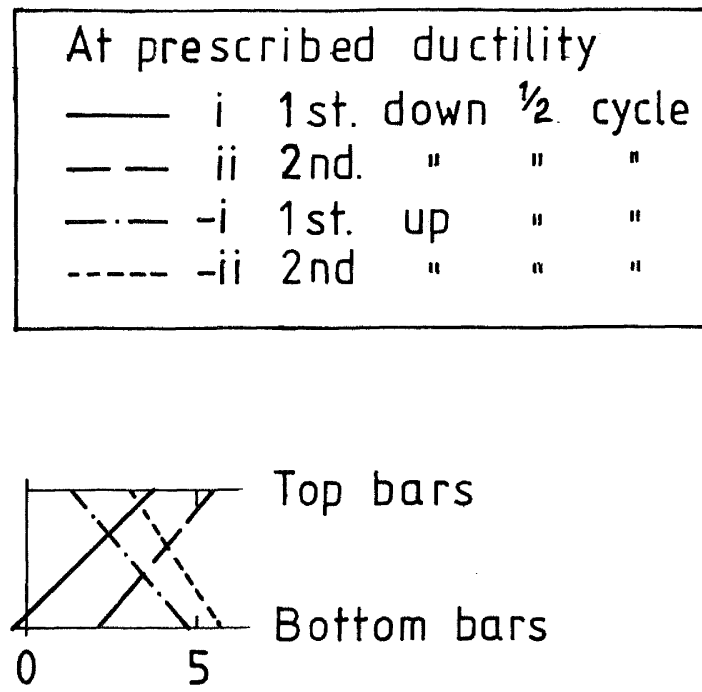

DUCTILITY OF 2

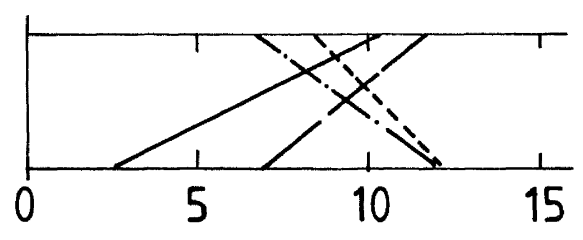

DUCTILITY OF 4

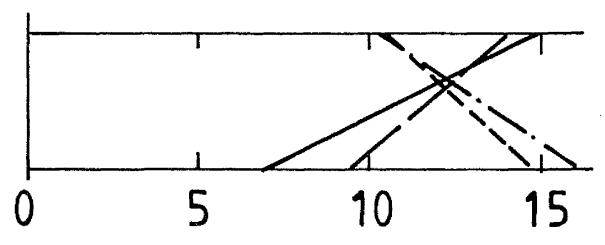

DUCTILITY OF 6

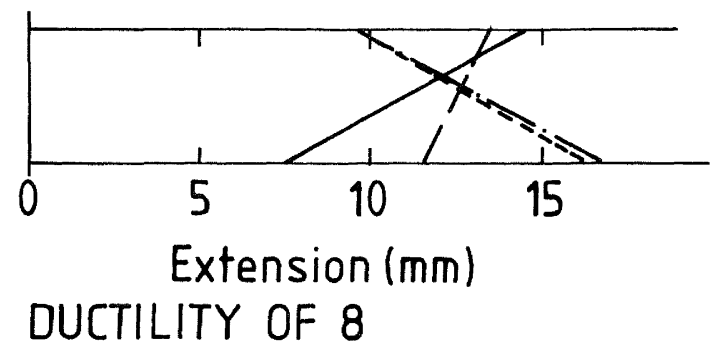

(b) Reversing plastic hinge

Figure 5 Elongation of reinforcement in plastic hinge zones. 
Figure 6 shows the measured and predicted elongations in the beam test together with some further results obtained from the test of a reinforced concrete portal, which developed unidirectional plastic hinges when subjected to cyclic loading. The test of this portal is briefly described later and has been fully described in a previous paper(5). It can be seen that equation 2 gives a good estimate of the elongation for both the portal frame and the beam. It over estimates elongation when the reinforcement starts to buckle. During the test of the portal frame the axial load in the beam varied between a compression

force of $0.045 \mathrm{~A}_{\mathrm{g}} \mathrm{f}_{\mathrm{c}}^{\prime}$ and a tension force of $0.022 \mathrm{~A}_{\mathrm{g}} \mathrm{f}_{\mathrm{c}}^{\prime}$.

This variation did not influence the elongation to any appreciable extent.

The pattern of strains in the flexural reinforcement in a reversing plastic hinge is markedly different from that in a unidirectional plastic hinge, see Figure 5(b). When the initial inelastic displacement is applied it acts as a uni-directional plastic hinge and a small compression strain is sustained by the compression zone reinforcement. With the reversal of the loading direction the reinforcement in the compression zone, which had been yielding in tension in the previous half cycle did not fully yield back in compression. With continued cyclic loading the compression reinforcement continues to elongate. This results in the cracks in the compression zone remaining open. For the reversing hinge the elongation at mid-depth is given by -

$$
\text { extension }=e+\Sigma \theta\left(d-d^{\prime}\right) / 2
$$

where $\mathrm{e}$ is the elongation of the reinforcement in the compression zones of the plastic hinges in the beam. From the experimental results shown in Figure 5(b) it can be seen that the elongation " $\mathrm{e}$ " makes a major contribution to the axial extension of the beam. In this test it accounted for over twice the extension arising from the plastic hinge rotation in the 4,6 and 8 displacement ductility cycles. That is, the elongation was approximately three times the value given by equation 2 .

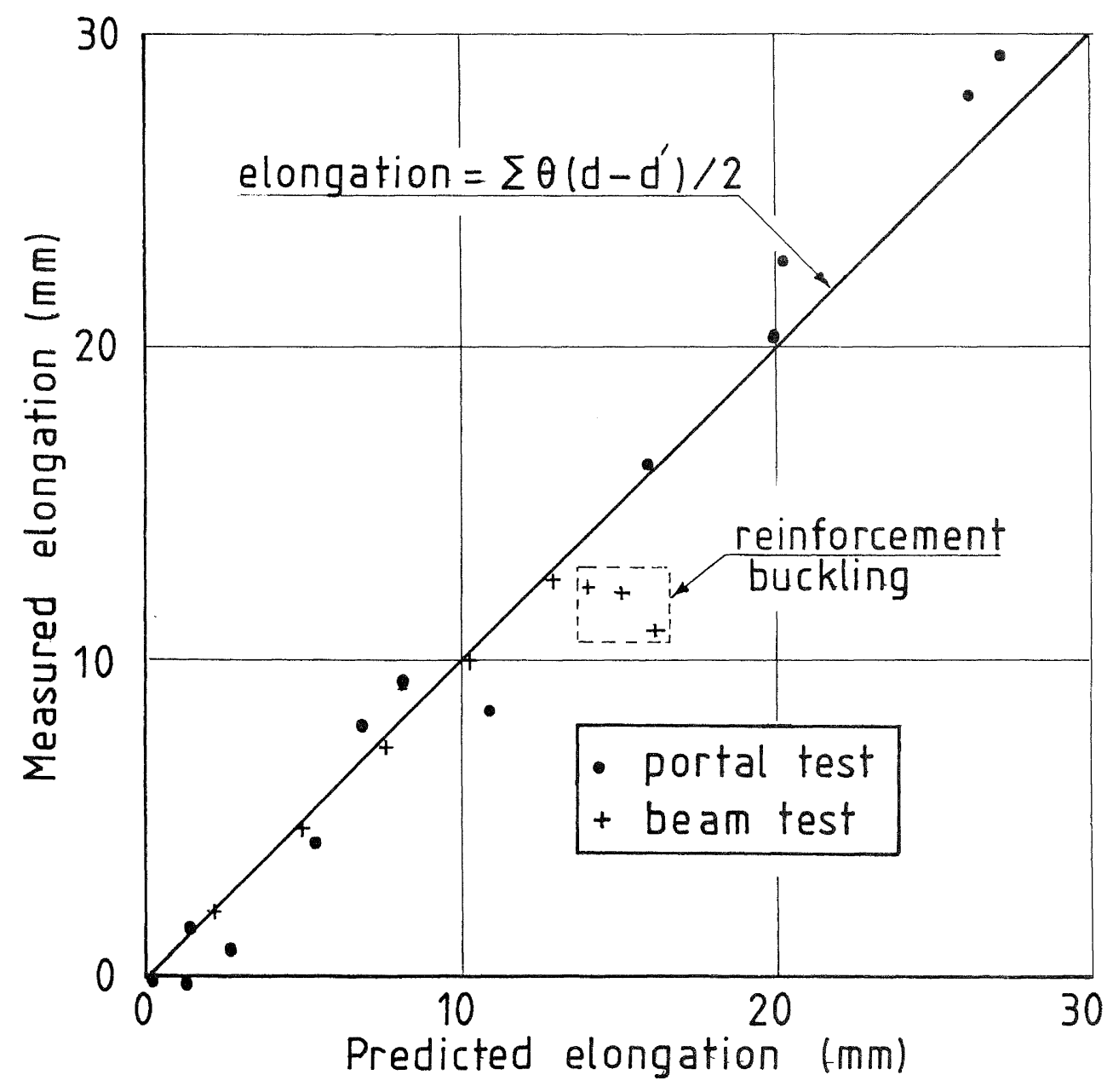

Figure 6

Predicted and measured elongations in beams forming uni-directional plastic hinges. 
There are two reasons why the longitudinal reinforcement in the compression zone of a reversing hinge does not fully yield back, thus preventing the cracks in the compression zone from closing. The first of these arises from the wedging action of the aggregate particles, which become dislocated in the cracks, and the second results from the mechanism of shear resistance in the hinge zone. With the formation of the intersecting diagonal cracks in this region the shear resistance is provided by a truss like action, which is illustrated in Figure 7. From the equilibrium requirements associated with the truss action it can be seen that the flexural compression force, $\mathrm{C}$, is always smaller than the flexural tension force, $\mathrm{T}$, at the same section. In fact this compression force is equal to the flexural tension force minus the longitudinal component of the diagonal compression forces in the web of the beam. Consequently the inelastic rotation in the hinge zone tends to occur more by yielding of the reinforcement in tension than in compression. Under cyclic conditions this results in an overall longitudinal extension from one cycle to the next.

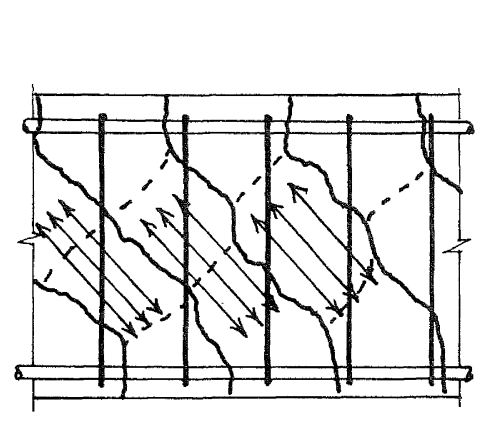

(a) Diagonal compression

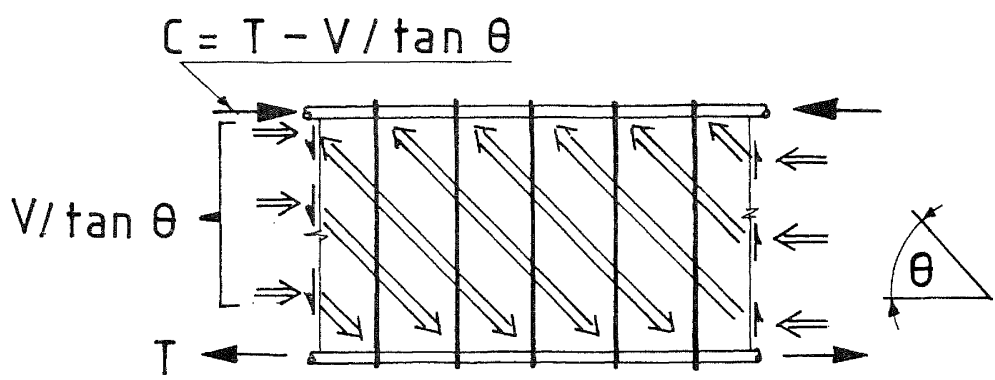

(b) Truss action
The test results show that the beams with unequal areas of top and bottom reinforcement sustain slightly greater elongations when the larger area of steel is in compression and slightly smaller elongation when the smaller area is in compression than the corresponding beams with equal top and bottom reinforcement areas. The slab in beam Ta $4 \mathrm{~B}$ proved to be ineffective in restraining elongation as once some of the reinforcement in it yielded, due to composite action with the beam, it acted to prop open the cracks when the direction of flexure reversed.

Figure 9 shows the results of some beam tests, which were carried out under differing axial load levels. In Figure 9(a) the elongation measured during the test is plotted against the peak displacement ductility applied to the beam, showing decreasing elongation for increasing axial load ( 0 to $\left.0.145 \mathrm{~A}_{\mathrm{g}} \mathrm{f}_{\mathrm{c}}^{\prime}\right)$. In part (b) the elongation is shown as a function of the rotation of the plastic hinge zone. The elongation predicted by equation 3 is

Figure 7 Shear resistance in a plastic hinge zone.

\section{THE INFLUENCE of UNEQUAL FLEXURAL REINFORCEMENT AREAS, COMPOSITE SLABS and AXIAL FORCES on ELONGATION}

Figure 8 (b) shows the results of measurements of elongation made on three cantilever beams which were tested under cyclic loading conditions so that reversing plastic hinges formed(8). Two of these beams were rectangular. The first one, beam Ta $1 \mathrm{~B}$, was reinforced with five $20 \mathrm{~mm}$ deformed longitudinal bars in both the top and bottom of the beam. Beam Ta $2 \mathrm{~B}$ had five $20 \mathrm{~mm}$ bars as top reinforcement and three $20 \mathrm{~mm}$ bars as bottom reinforcement. The third beam, Ta 4B, had a Tee shaped cross-section. The longitudinal reinforcement in the web was identical to that contained in beam Ta 1B. The flange was reinforced with ten $10 \mathrm{~mm}$ deformed bars. The beam crosssections are shown in Figure 8(a). The ratio of the longitudinal steel on the bottom of the beam to that at the top of the beam is 1.0 for beam Ta $1 \mathrm{~B}$ and 0.60 for beam Ta $2 \mathrm{~B}$ and 0.67 for the Tee beam, (Ta 4B). shown for the case where the compression reinforcement yields back so that the crack in the compression zone just closes, that is $\mathrm{e}$ is zero in equation 3 .

The test results shown in Figure 9 were obtained from two series of tests. Beams T2A, T3A and T3B $(500 \times 200 \mathrm{~mm}$ with $\rho=\rho^{\prime}=1.78 \%$ ) were tested dynamically at speeds compatible to those that would be expected in a major earthquake(9), while beam S1B, with identical section properties, was tested slowly over a period of two days. The results show that the axial load level has a marked influence on the elongation of the plastic hinge zone. Interpolating between the values it appears that an axial force of about $300 \mathrm{kN}$ should have been sufficient to just close the cracks in the compression zone. Of this value close to $140 \mathrm{kN}$ would be required to eliminate the difference in the magnitudes of the tension and compression forces due to the truss action associated with shear (see Figure 7). This leaves

$160 \mathrm{kN}$, or $0.05 \mathrm{~A}_{\mathrm{g}} \mathrm{f}_{\mathrm{c}}^{\prime}$, to overcome the wedging action of the dislocated aggregate particles in the cracks. On this basis it appears that the axial force, $F_{c}$, necessary to just close the cracks in the compression zone is given by the expression -

$$
F_{c}=V_{o}+0.05 A_{g} f_{c}^{\prime}
$$

where $\mathrm{V}_{\mathrm{o}}$ is the shear force associated with overstrength actions in the hinge zone. 

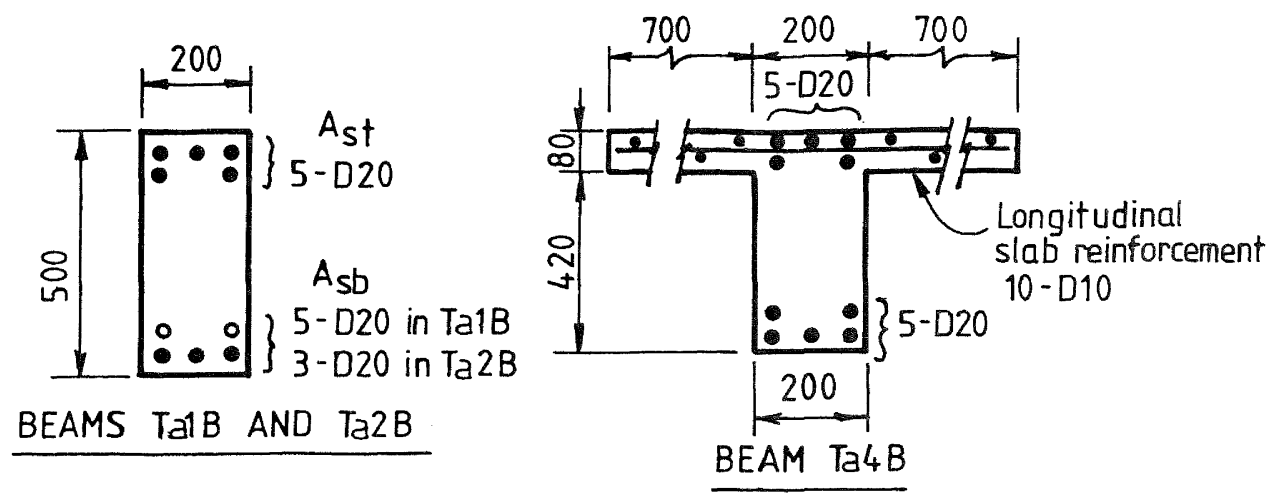

(a) Beam sections.
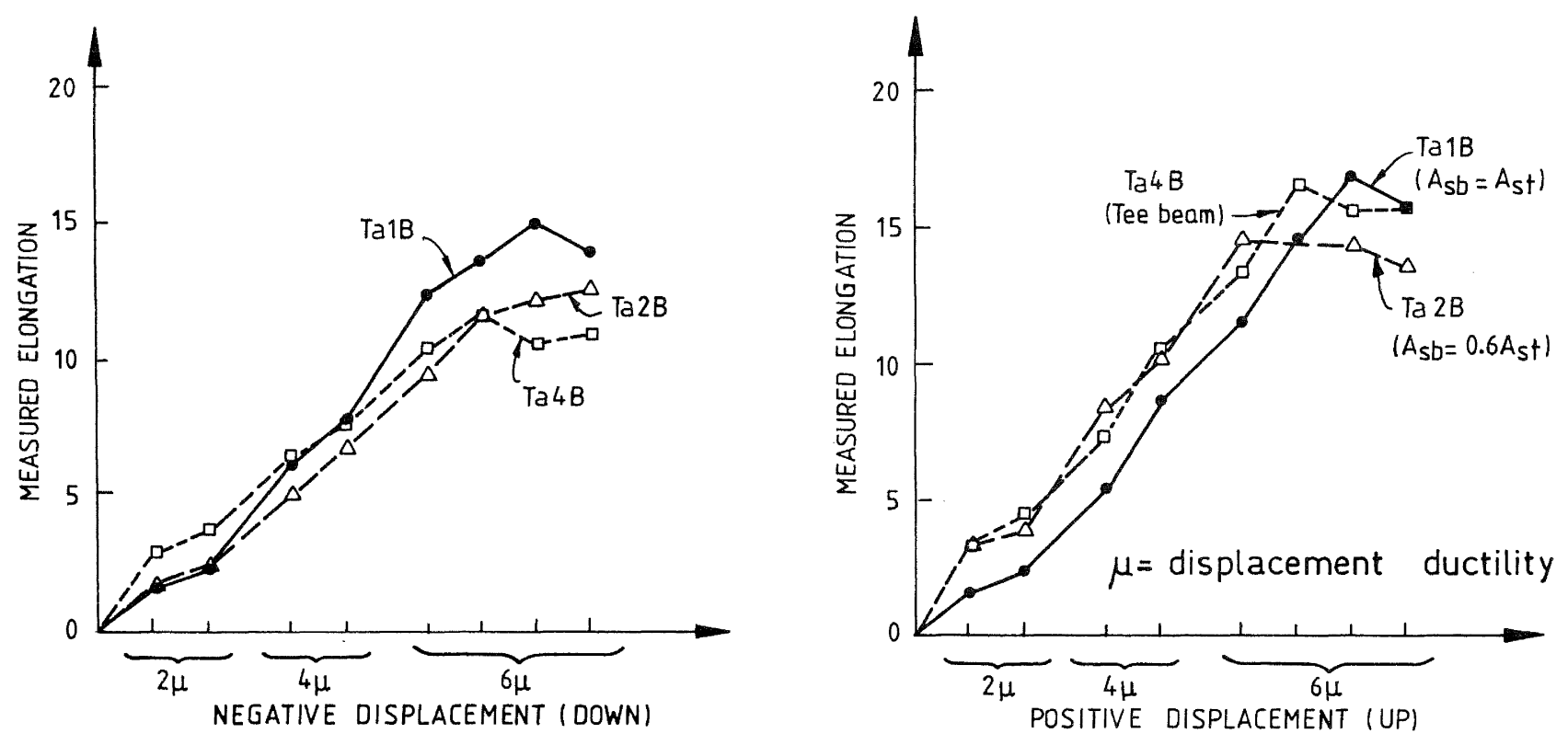

(b) Elongation measurements.

Figure 8

Elongation in beams with unequal top and bottom reinforcement areas. 


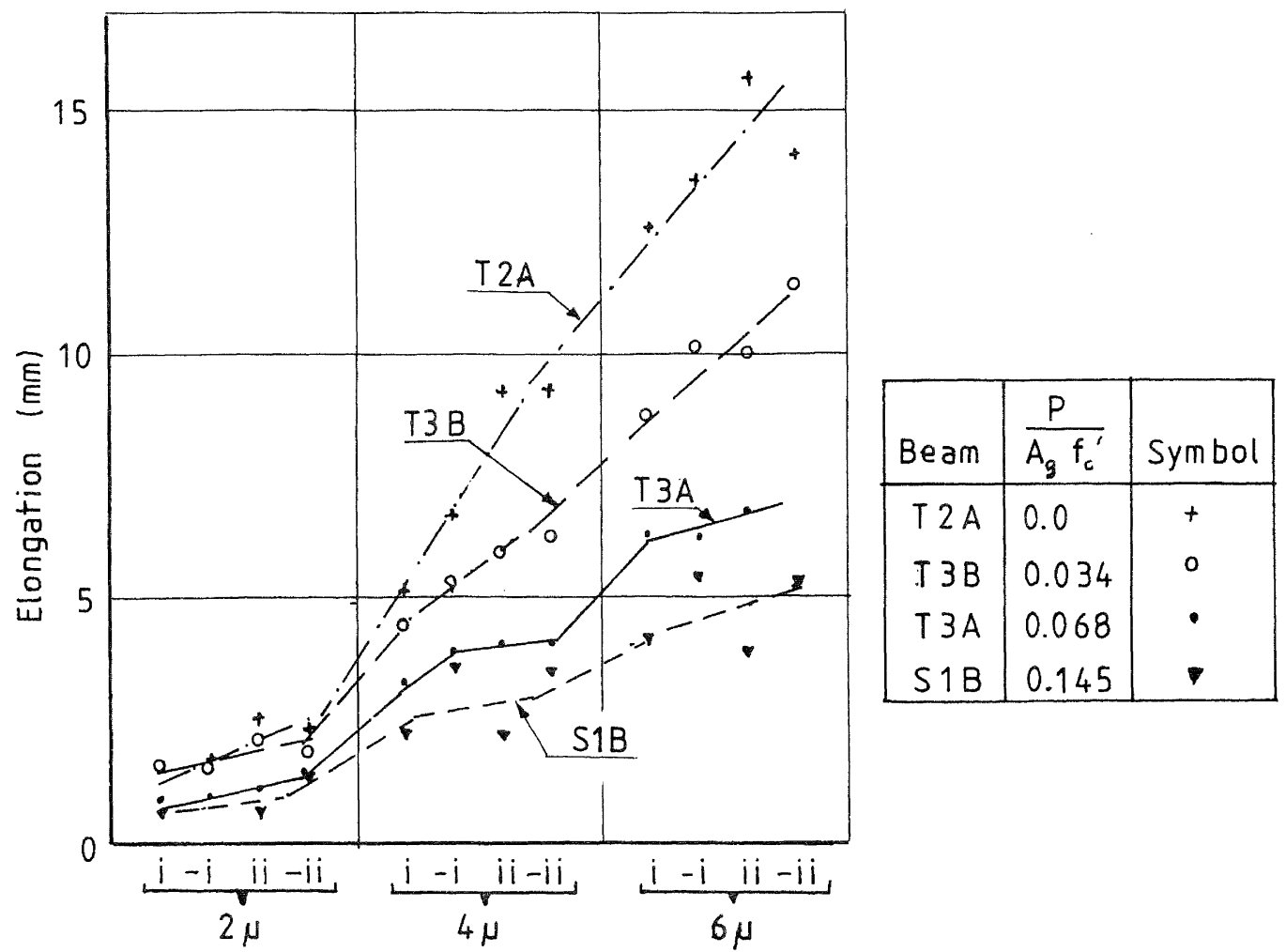

(a) Displacement ductility

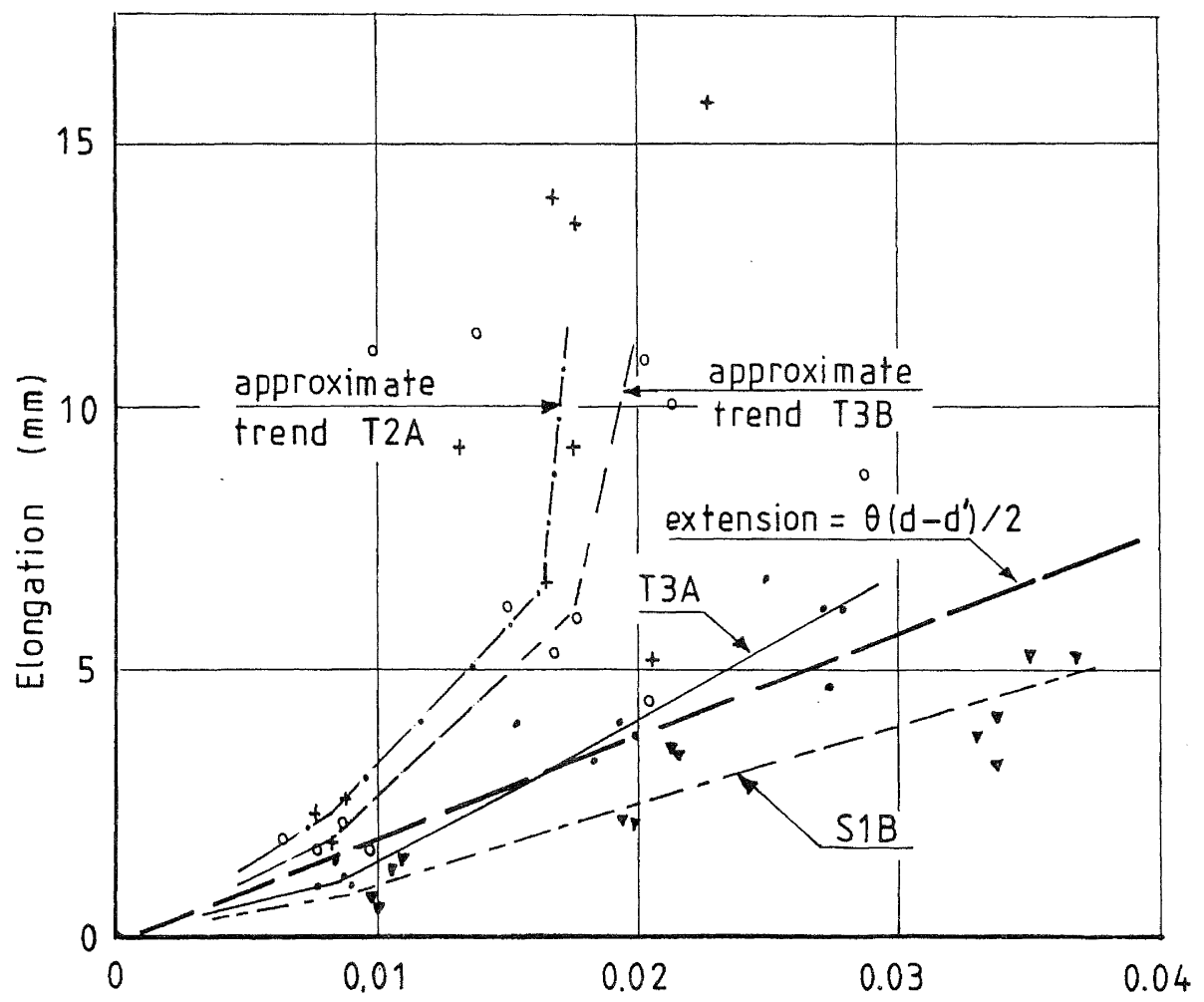

(b) Plastic hinge rotation (radians)

Figure 9 Elongation of beams sustaining different levels of axial force. 


\section{LOAD DEFLECTION CHARACTERISTICS ASSOCIATED WITH REVERSING and UNI-DIRECTIONAL PLASTIC HINGES}

Instrumentation in the form of displacement transducers was fixed to the beams as shown in Figure 4(b). The measurements obtained from these were used to calculate the components of flexural and shear displacements at the jacking point during testing. The sum of these two values gives the calculated displacement at the load point. As this displacement was also measured directly an overall check existed on the accuracy of the measurements. The discrepancy between the calculated and measured displacements is shown on Figs. 10 and 11 as the 'closure error'.

From the displacement measurements made on the longitudinal reinforcement of the two beams shown in Figure 5, it can be seen that there is a marked difference in the flexural rotation sustained at comparable displacements. The first time a displacement ductility of 8 is reached the flexural rotation in the uni-directional hinge is two and a half times the corresponding value in the reversing hinge. This difference arises from the very different response to shear of these two types of plastic hinge.
The sums of the measured flexural and shear displacements at the peak half cycle deflections, which are shown as the calculated displacements, are compared in Figures 10 and 11 to the deflections measured at the load points. From these two figures it can be seen that much more shear deformation occurs in the reversing hinge than in the uni-directional hinge. In the reversing hinge the shear deformation accounted for 50 percent of the total deflection in the second ductility 4 cycle $(4 \mu$ (ii) and $4 \mu(-\mathrm{ii}))$ and in the last ductility 8 cycle this increased to 77 and 58 percent of the deflection for the two loading directions, ( $8 \mu$ (ii) and $8 \mu$ (-ii) respectively). For the uni-directional hinge the shear deformation accounted for close to 19 percent of the total deflection up to the end of the ductility 10 load cycles. At failure in the first cycle to ductility 14 the shear deformation had increased to 29 percent.

The two beam tests showed that appreciably greater rotations can be sustained by uni-directional hinges than reversing hinges. Strength degradation occurred in the first ductility 14 load cycle in the beam with the uni-directional hinge while the corresponding degradation point with the reversing hinge occurred in the second ductility 8 load cycle. This difference in deflection capability is reflected in the maximum rotation sustained by the two beams. The uni-directional hinge underwent a $3.6^{\circ}$ rotation while the corresponding value for the reversing hinge was less than one third of this value.

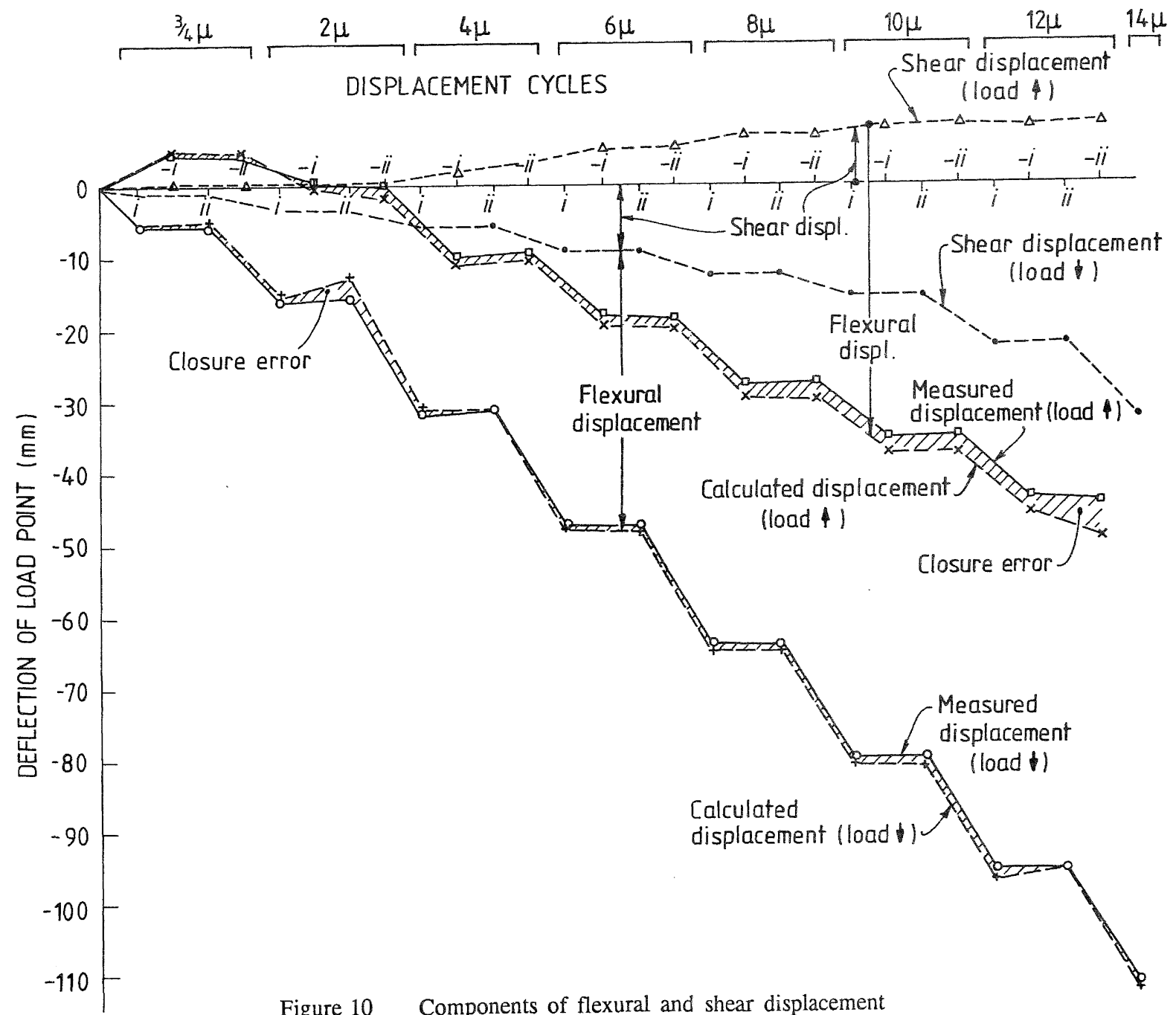

Figure 10 Components of flexural and shear displacement sustained at the peak displacements in each load cycle in the beam with the uni-directional plastic hinge. 


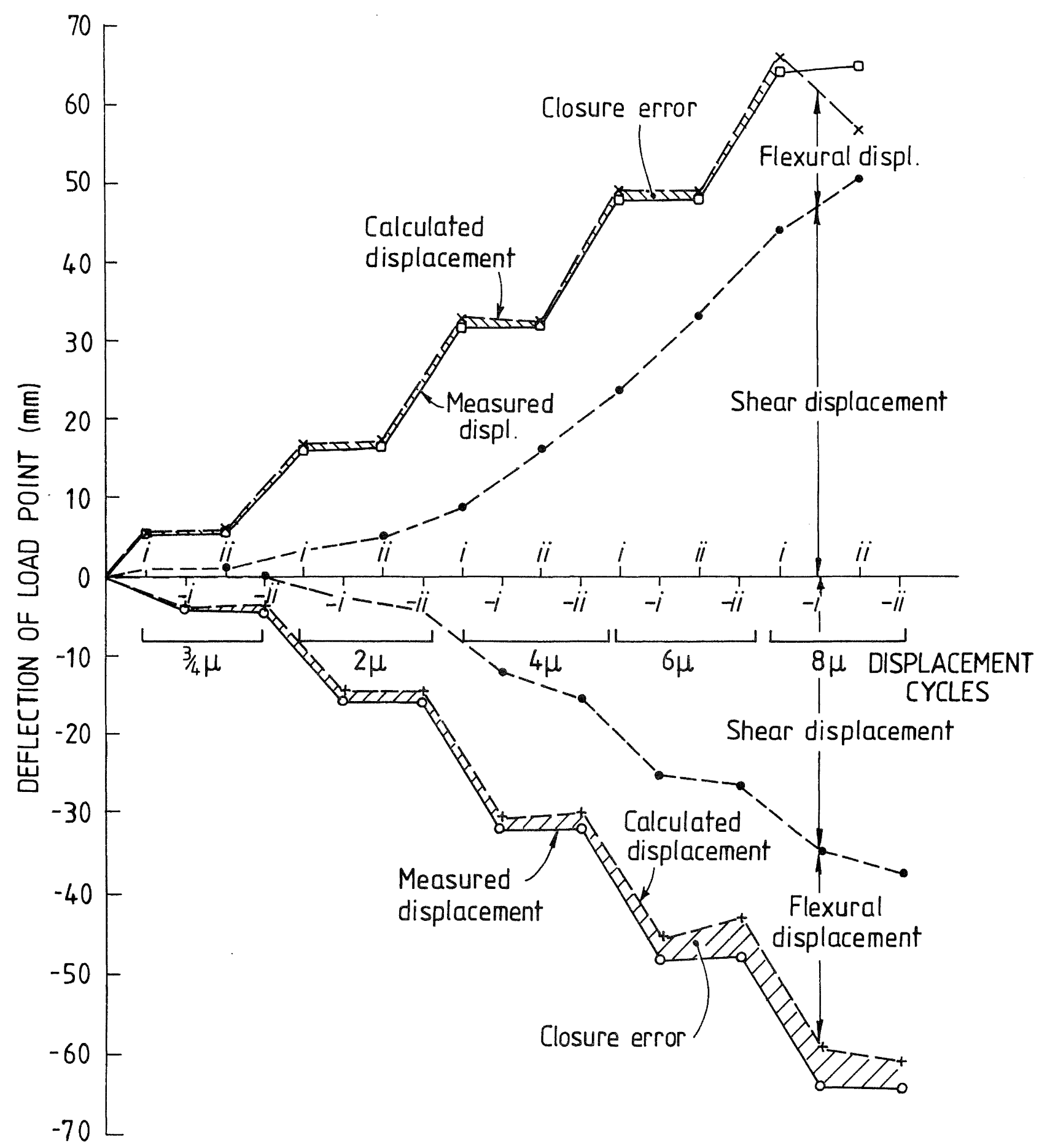

Figure 11 Components of flexural and shear displacement sustained at the peak displacements in each load cycle in the beam with the reversing plastic hinge. 
As part of an investigation into the seismic performance of structures which form uni-directional plastic hinges in a severe earthquake, a reinforced concrete portal frame was built and tested(5). The $500 \times 250 \mathrm{~mm}$ beam was reinforced top and bottom with two D24s and a D28 bar (reinforcing ratio = $1.34 \%$ ) over its length and the transverse shear reinforcement was sets comprising a R10 closed stirrup together with a R10 supplementary tie, each set spaced at $140 \mathrm{~mm}$ centres $\left(\rho_{\mathrm{v}}=\right.$ 0.0067). The beam-column joints were designed to remain elastic throughout testing by welding two lengths of D10 bar on each of the principal beam bars anchored in the joint zone. This prevented yield penetration into the joint zone. Two constant point loads were used to represent gravity loads from secondary beams positioned 1 metre either side of mid-span; see the test arrangement shown in Figure 12.

Simulated seismic forces were applied by jacking the structure backwards and forwards from a point just above beam level at one end. As the frame was displaced laterally the jacks applying the vertical forces were also displaced so that the lines of action of the jack forces were inclined to the vertical. With this arrangement no P-delta effects were induced. Predominantly uni-directional beam hinges formed when the cyclic lateral force was applied. Negative moment hinge rotations accumulated near the column faces while positive moment hinge rotations accumulated close to where the vertical forces were applied.

The progressive increase in plastic hinge rotations, with every cycle of lateral loading, was reflected in the increasing mid-span downward deflection, which reached $60 \mathrm{~mm}$ (1.1\% of the span) during the second cycle at ductility 6 . The measured beam elongation was between 30 and $40 \mathrm{~mm}$ near the end of testing depending on the direction of application of the lateral force. At this stage displacements of $\pm 55 \mathrm{~mm}$ were being applied to the portal. The lateral force versus lateral displacement hysteresis plot is shown in Figure 13.
Buckling of the reinforcement in compression in one of the negative moment plastic hinge zones lead to the lateral strength being reduced to less than $80 \%$ of the theoretical strength. This failure occurred when a plastic hinge rotation of $4.8^{\circ}$ was being sustained.

An interior beam-column sub-assemblage which formed reversing plastic hinges when tested makes an interesting comparison with the portal frame described above, where unidirectional hinges formed in the beams. The cruciform shaped specimen, described in reference 10 , had $500 \times 250 \mathrm{~mm}$ beams with equal top and bottom principal reinforcement comprising two D28s and one D24 bar, $\left(\rho=\rho^{\prime}=1.48 \%\right)$. The beam's shear reinforcement comprised a R10 closed stirrup with a R6 supplementary tie together spaced at $100 \mathrm{~mm}$ centres along the beam $\left(\rho_{\mathrm{v}}=0.0074\right)$. As in the portal frame test the joints were detailed to remain elastic by welding two extra D12 bars and 90 x $90 \times 25$ bond plates to the D28 beam bars through the joint zone. The extra D12 bars extended $170 \mathrm{~mm}$ out from the column faces. The beams were cyclically loaded near their ends ( 2.235 metres from the column centreline) with a loading pattern similar to that used in the portal frame and reversing hinge beam tests.

As expected, reversing hinges formed in the beams close to the column faces and the unit's lateral force versus lateral displacement plot is reproduced in Figure 14. The hysteretic behaviour was very similar to that of the cantilever beam loaded to form a reversing hinge. The sub-assemblage suffered progressive stiffness degradation and increasing shear deformation in the plastic hinge zones as the testing progressed. This stiffness degradation was found to be largely a function of the shear deformation that develops in reversing hinge zones(10). The pinched nature of the load deflection curves of this unit is in sharp contrast to the load deflection traces of the portal frame. In the latter case, the shear pinching in the load deflection curves did not occur as the shear force on each hinge zone did not reverse. As a consequence there was very little stiffness degradation with the portal frame until failure was imminent and the longitudinal reinforcement started to buckle.

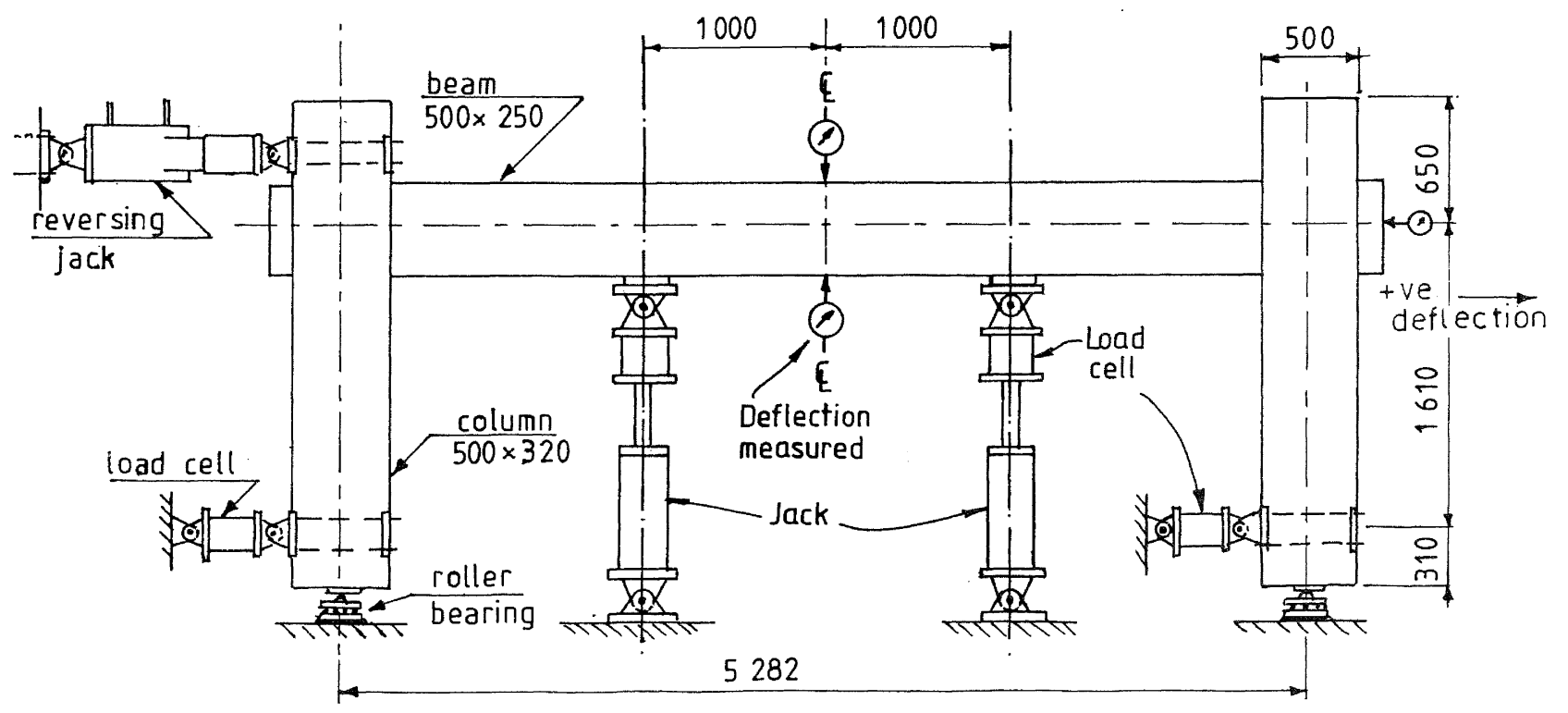

Figure 12 Test arrangement for portal frames. 


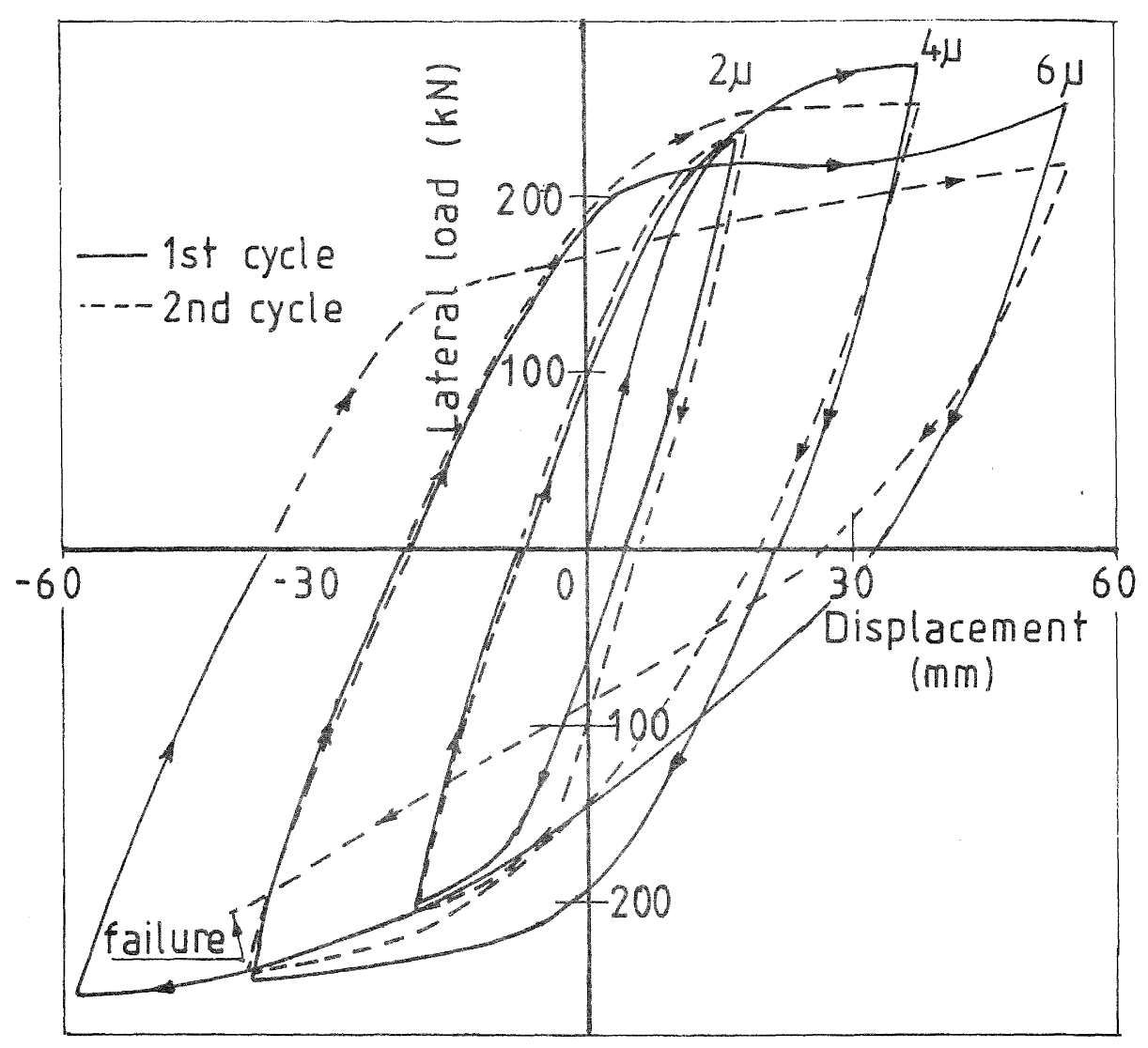

Figure 13 Lateral force versus lateral displacement for the portal frame.

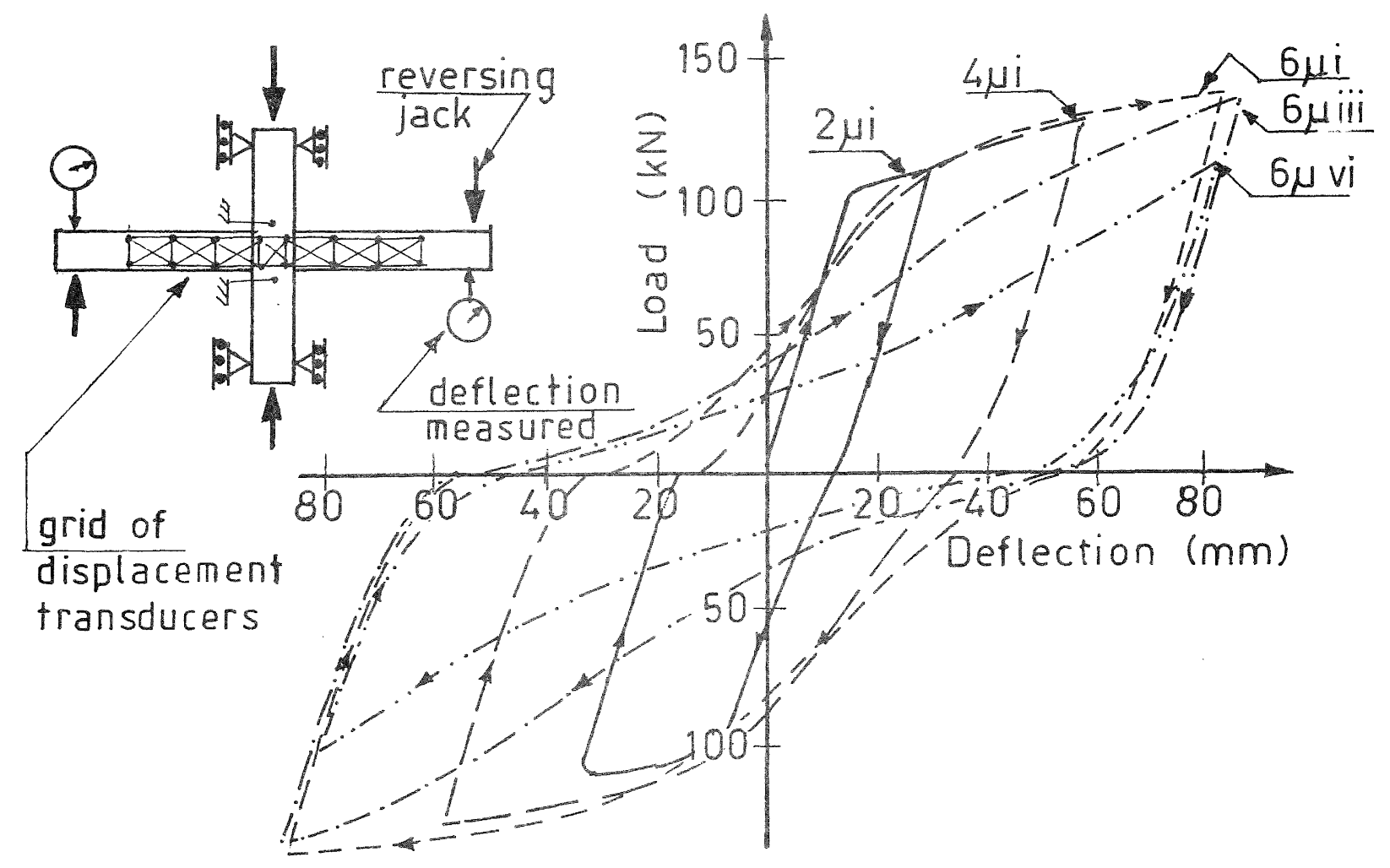

Figure 14 Force versus displacement for selected load cycles in the beamcolumn sub-assembly. 


\section{DISCUSSION and CONCLUSIONS}

(a) Two different types of plastic hinge zone may form in the beams of seismic resistant structures, namely reversing and uni-directional hinges.

(b) Frames which develop reversing hinges may be expected to sustain a marked loss of stiffness during the passage of the earthquake. In contrast very little stiffness degradation may be expected where the majority of the plastic hinges are of the uni-directional form.

(c) With both uni-directional and reversing plastic hinges inelastic rotation occurs predominately due to the tensile yielding of the reinforcement rather than crushing of the concrete. This causes the plastic hinge zones to elongate.

(d) In beams with an overall depth of $500 \mathrm{~mm}$ the elongation sustained in each plastic hinge zone was of the order of $15 \mathrm{~mm}$ before strength degradation occurred.

(e) For beams which sustained reversing hinges the magnitude of the elongation was not significantly changed by having different areas of longitudinal top and bottom reinforcement, be it in a rectangular beam or in a beam with a composite slab.

(f) In uni-directional hinge zones the application of light axial loads, in the range of $0.045 \mathrm{~A}_{\mathrm{g}} \mathrm{f}_{\mathrm{c}}^{\prime}$ in compression to $0.022 \mathrm{~A}_{\mathrm{g}} \mathrm{f}_{\mathrm{c}}^{\prime}$ in tension were found to have no significant influence on the elongation which developed.

(g) In reversing hinge zones the application of a light axial load to the beam (in the range of 0 to $0.145 \mathrm{~A}_{\mathrm{g}} \mathrm{f}_{\mathrm{c}}^{\prime}$ ) was found to reduce but not eliminate elongation.

(h) The effects of elongation are generally ignored in the analysis of structures. With the magnitude of this action measured in the described tests, elongation can be expected to have a major influence on the seismic performance of concrete structures, including the repairability of the damaged structure and the possible additional damage to non-structural elements. Also beam elongation is likely to cause changes in the bending moment's distribution allowing hinges to form in columns just below first floor level.

(i) The inelastic rotation that a uni-directional plastic hinge zone can sustain is appreciably greater than that sustained by a reversing plastic hinge zone. However, this does not lead to an increased ductitlity as the rotation demands imposed on uni-directional plastic hinge zones are significantly greater than those imposed on reversing hinge zones(7).

\section{REFERENCES}

1. Zerke, H.E. and Durrani, A.J., "Seismic response of connections in two bay reinforced concrete frame subassemblies", Journal of Structural Engineers, ASCE. Vol. 115, No. 11, Nov. 1989, pp 2829-2844.

2. Zerke, H.E. and Durrani, A.J., "Seismic response of connections in two bay reinforced concrete frame subassemblies with a floor", Structural Journal, American Concrete Institute, Vol. 87, No. 4, July-Aug. 1990, pp 406-415.

3. Wight, J.K. (editor), "Earthquake effects on reinforced concrete structures", American Concrete Institute, SP84, 1985, 428p.

4. Fenwick, R.C. and Fong, A., "The behaviour of reinforced concrete beams under cyclic loading", Bulletin of NZ National Society for Earthquake Engineering, Vol. 14, No. 3, Sept. 1981, pp 145-159.

5. Megget, L.M. and Fenwick, R.C., "Seismic behaviour of a reinforced concrete portal frame sustaining gravity loads", Bulletin of NZ National Society for Earthquake Engineering, Vol. 22, No. 1, Mar. 1989, pp 39-49.

6. Restrepo, J., Park, R. and Buchanan, A., "Seismic load tests on midspan connections between precast concrete beams", NZ Concrete Society, Technical Report TR10, Sept.1990, pp 55-71.

7. Fenwick, R.C. and Davidson, B.J., "Moment redistribution in seismic resistant concrete frames", Proceedings Pacific Conference on Earthquake Engineering, Wairakei, 1987, Vol. 1, pp 95-106.

8. Fenwick, R.C., Tankat, A.T. and Thom, C.W., "Deformation of reinforced concrete beams subjected to inelastic cyclic loading", University of Auckland, School of Engineering Report No. 268, Oct. 1981, 72p.

9. Thom, C.W., "The effects of inelastic shear on the seismic response of structures", University of Auckland, School of Engineering Report No. 347, Mar. 1984, 204 p.

10. Fenwick, R.C. "Seismic resistant joints for reinforced concrete structures", Bulletin of NZ National Society for Earthquake Engineering, Vol. 14, No. 3, Sept. 1981, pp 145-159. 